https://doi.org/10.32541/recie.2018.v2i2.pp94-106

\title{
PELOTÁO, ALTO! MILITARIZAÇÁO COMO RESPOSTA AOS CASOS DE VIOLÊNCIA ESCOLAR NO BRASIL
}

\section{Squad, stop! Militarization as an answer to cases of school violence in brazilian}

- Rodrigo Grazinoli Garrido*

Universidade Católica de Petrópolis

Universidade Federal do Rio de Janeiro, Brasil

\grazinoli.garrido@gmail.com

(iD) https://orcid.org/0000-0002-6666-4008
- Klever Paulo Leal Filpo

Universidade Católica de Petrópolis

Universidade Federal Rural do Rio de Janeiro, Brasil

■Klever.filpo@yahoo.com.br

https://orcid.org/0000-0001-6882-4282

\section{Resumo}

O artigo se propóe a problematizar e refletir sobre iniciativas recentes de governos estaduais e locais, no Brasil, que envolvem, em maior ou menor grau, a militarização de escolas públicas como medida destinada a coibir casos de violência nessas instituições de ensino. Combina resultado de revisão bibliográfica com informaçóes retiradas de matérias jornalísticas e dados de campo, estes últimos provenientes de pesquisa empírica qualitativa realizada no município de Petrópolis, estado do Rio de Janeiro, Brasil. Foi possível reconhecer que, apesar do necessário respeito ao interesse, cada vez maior, de famílias por um ensino militarizado, a opção por resolver conflitos escolares dessa forma pode não ser adequada, mas pelo contrário recrudescer as animosidades, afastando a escola de seu papel principal.

Palavras chave: conflitos escolares, segurança pública, violencia, militarização.

\begin{abstract}
The article proposes to problematize and stimulate reflections on recent initiatives of state and local governments in Brazil that involve, to a greater or lesser extent, the militarization of public schools as a measure to curb violence in these educational institutions. It combines bibliographical review results with information taken from journalistic materials and field data, the latter from qualitative empirical research carried out in the city of Petrópolis, state of Rio de Janeiro, Brazil. It was possible to recognize that, despite the necessary respect for the growing interest of families through a militarized education, the option to solve school conflicts in this way may not be adequate, but rather to intensify the animosities, away from the school's main role.
\end{abstract}

Keywords: school conflicts, public security, violence, militarization.

ISSN (impreso): 2636-2139

ISSN (en línea): 2636-2147

Sitio web: https://revistas.isfodosu.edu.do/recie
* Autor de correspondencia

Recibido: 17 octubre 2018

Aprobado: 04 diciembre 2018

\section{COMO CITAR:}

Grazinoli Garrido, R., \& Leal-Filpo, P. (2018). Pelotão, alto! militarização como resposta aos casos de violência escolar no Brasil. Revista Caribeña de Investigación Educativa (RECIE), 2(2), 94-106. https://doi.org/10.32541/recie.2018.v2i2.pp94-106 


\section{Introdução}

Ítalo Cardoso, de 9 anos, apertou ligeiramente o passo no começo daquela tarde de 14 de junho. Ele não queria chegar atrasado à escola. Um minuto de atraso poderialhe render uma anotação de infração no boletim escolar. Ao se aproximar do colégio, Ítalo ajeitou a farda com destreza. Enquanto caminhava em direção a dois militares para bater continência, assentou na cabeça a boina marrom, limpa e bem asseada, para que nenhuma ponta de cabelo ficasse à mostra. Na porta da escola, um militar parrudo fez uma breve revista no menino e o liberou para se juntar a 700 colegas que se encontravam em fila indiana e divididos em dois pelotóes. Gritos de guerra, hasteamento da bandeira e hinos nacionais deram continuidade ao ritual de entrada de Ítalo na escola, similar ao de um quartel. (Camporez, 2018)

O relato ilustra a realidade do Colégio Estadual Waldemar Mundim, na periferia de Goiânia, capital do estado de Goiás, Brasil, onde Ítalo cursa o ensino fundamental. Não se trata de um colégio militar, mas sim de uma escola pública estadual (administrada pelo Governo Estadual) que foi transferida para o "Comando" da Polícia Militar do estado de Goiás. Partindo dessa exposição, o artigo se propôe a identificar e despertar reflexóes sobre iniciativas recentes de governos estaduais e locais, no Brasil, que envolvem, em maior ou menor grau, a militarização de escolas públicas, como medida destinada a coibir casos de violência nessas escolas.

Metodologicamente, o texto combina resultado de revisão bibliográfica com informações retiradas de matérias jornalísticas difundidas por veículos de comunicação de grande porte, no Brasil, assim como alguns dados de campo. Estes últimos são provenientes de pesquisa empírica qualitativa em andamento na cidade de Petrópolis, RJ, com recursos do CNPq-Brasil. Tal pesquisa se destina a compreender como surgem e como são administrados os conflitos escolares nesse município, e as circunstâncias que os levam a transformar-se até mesmo em açóes cíveis e criminais, com graves repercussóes para os envolvidos.

Em um primeiro momento, o texto se ocupa de conceituar a violência escolar, em suas diferentes vertentes. Tal esforço se justifica pelo fato do termo violência ser, por si, de difícil conceituação, polissêmico e controverso. Seus significados são variados e pode se referir a fenômenos completamente distintos. Da mesma forma, a chamada violência escolar comporta uma diversidade de definiçóes. De acordo com Da Silva e Assis (2018), remontando uma gama de autores, atos de violência física, violência verbal, contrariedade aos preceitos escolares, depredação, comportamentos anti-sociais e até crimes, são enquadrados nesse contexto. Certamente, este fenômeno náo pode ser entendido apartado das relaçóes sociais que cercam a escola, com as especificidades escolares.

Em um segundo momento, o artigo apresenta e coloca sob discussáo iniciativas de militarização de escolas públicas como forma de enfrentamento e prevenção da violência. Nessa parte, distingue os colégios militares das escolas públicas as quais vêm ganhando feições militares, sob administração militar. Na sequência, o texto problematiza essas iniciativas e traz, ao final, algumas consideraçóes que têm em conta o papel institucional das escolas na formação de cidadãos.

$\mathrm{O}$ artigo faz um exercício de estranhamento sobre a proliferação de propostas de militarização da gestão da segurança pública, nos mais diferentes setores, incluindo a administração das escolas e a militarização de suas propostas pedagógicas. De modo especial o artigo exercita um estranhamento 
sobre a introdução da Ordem Unidade, atividade tipicamente militar, como parte de algumas estratégias pedagógicas.

Por fim, o texto coloca sob discussão a ideia de que o militarismo poderia resolver problemas gerais relacionados à violência em qualquer área do convívio social, incluindo a educação, o que é questionado por pedagogos e educadores.

\section{Violência e Conflito Escolar no Brasil}

No senso comum, conceitua-se o fenômeno violento como algo negativo, não desejável, originado da relação entre homens em que prevalece a força no lugar da cooperação, afeto, solidariedade e comunicação (Garrido e Giovanelli, 2015). Por este caminho, é possível entender a violência como sendo representada por açôes humanas realizadas por indivíduos, grupos, classes, nações, numa dinâmica de relaçóes, ocasionando danos físicos, emocionais, morais e espirituais a outrem (Minayo, 2003).

De acordo com a Organização Mundial da Saúde, a violência pode ser definida como:

[o] uso intencional da força física ou do poder, real ou potencial, contra si próprio, contra outras pessoas ou contra um grupo, ou uma comunidade, que resulte ou tenha grande possibilidade de resultar em lesão, morte, dano psicológico, deficiência de desenvolvimento ou privação. (OMS, 2002)

Para Charlot (2002, p. 434), quando se trata de violência escolar, é preciso, inicialmente, distinguir a violência na escola, a violência à escola e a violência da escola. A primeira, ocorrida dentro da escola sem relação com a natureza ou atividades da escola. Já a violência à escola ocorre contra à instituição ou a seus representantes, sendo provocada por seu corpo social e, assim, relaciona-se à natureza e às atividades escolares. Por fim, teríamos a violência da escola, que é resultado da ação escolar, prejudicando sua comunidade e podendo trazer consequências deletérias até mesmo para a formação dos alunos.

Nota-se, assim, que a conceituação de violência pode ser entendida nas relaçóes pessoais e institucionais. A despeito dos atos violentos sempre limitarem direitos, nem todos podem ser tipificados como crimes. No entanto, isto náo deve reduzir os esforços apenas à violência escolar criminosa, pois as vítimas de todas as outras formas de violência, certamente em maior número, ficariam desprotegidas (Da Silva e Assis, 2018). Além disso, a percepção das diversas formas de violência escolar deve servir para também diversificar as formas de prevenção, diagnóstico e enfrentamento a esse tipo de conflito.

Em ampla revisão sobre violência escolar, Da Silva e Assis (2018) reconheceram que as discussóes sobre o tema ainda são recentes no Brasil, datando da década de 1990, enquanto estudos sobre violência e escola remontam os anos de 1970 em países como EUA, França e Inglaterra. Além disso, essas autoras perceberam que a maior parte dos estudos está voltada para a avaliação de programas de prevenção da violência, com foco na violência entre estudantes, sem considerar a possibilidade de prevenção e o enfrentamento mais amplos do fenômeno.

No Brasil, tem sido comum que conflitos corriqueiros surgidos entre estudantes (uma discussão ocorrida durante uma partida de futebol, por exemplo) evoluam na forma de um espiral de violência. Alcança-se, com isso, açōes muito graves, envolvendo agressóes físicas e outras violaçôes 
de direitos que, não raro, chegam ao judiciário (Filpo, 2015). Aguinsky, Silva e Pacheco (2014) observaram que o incremento de crimes praticados por adolescentes também é acompanhado pela ampliação na judicialização (ingresso no sistema de justiça) de conflitos de baixo potencial ofensivo, como os escolares. Não raramente, conflitos nas escolas resultam na imposição de medidas socioeducativas aos envolvidos. Essa constatação parece trazer a reboque as demandas de alguns setores da sociedade brasileira por redução da idade penal, pois hoje, os menores de dezoito anos são penalmente inimputáveis (art. 228 da Constituiçáo da República Federativa do Brasil).

Contudo, as mesmas autoras constataram que, quando conflitos escolares são judicializados, nem sempre a dimensão educativa irá, necessariamente, prevalecer, havendo ainda que se levar em consideração a exposição dos adolescentes a toda sorte de constrangimentos e violências institucionais próprias à inserção no Sistema de Justiça e Segurança. Elas anotam que os conflitos escolares adentram o Sistema de Justiça Juvenil, e o seu tratamento exigiria a "articulação do Sistema de Garantia de Direitos da Criança e do Adolescente, no que se inclui Judiciário, Ministério Público, Delegacias de Polícia, Poder Executivo Municipal, Escolas e Conselhos de Direito e demais políticas públicas”. Assim, parece que a utilização de meios alternativos de solução dos conflitos escolares deveria prevalecer ao sistema de justiça na busca por resolução desse tipo de conflito - evitando-se, assim, consequências mais graves para os envolvidos e preservando os objetivos pedagógicos e socializadores da atividade escolar (Aguinsky, Silva e Pacheco, 2014).

No mesmo sentido, Teixeira (2011) menciona dados de pesquisa realizada no Brasil, no ano de 2008, pela International Plan Brasil, Organização náo Governamental (ONG) de proteçáo à infância. Nesse estudo, foram entrevistados cerca de doze mil estudantes de escolas brasileiras a respeito do tema da violência nas suas escolas. Cerca de setenta por cento dos alunos pesquisados afirmaram ter sido vítimas de violência escolar. Oitenta por cento apontaram suas escolas como violentas (p. 16).

Outra pesquisa, com cerca de 6.500 alunos dos últimos anos do ensino fundamental, ensino médio e Educação de Jovens e Adultos (EJA) em escolas dos municípios de Maceió (Alagoas), Salvador (Bahia), Fortaleza (Ceará), Vitória (Espírito Santo), São Luís (Maranhão), Belo Horizonte (Minas Gerais) e Belém (Pará), observou tipologia bastante diversa da violência escolar: violência verbal; furto; agressóes físicas são as expressões mais relatadas (Abramovay, 2016). Associado a este resultado, deve-se atentar para um outro dado deste levantamento: um percentual expressivo de alunos já levaram ou viram outros alunos levando armas à escola. Entre os tipos de armas, apontaram instrumentos contundentes, armas brancas e armas de fogo.

A despeito da violência escolar apresentar expressóes diversas, é possível que conflitos menos graves, se não solucionados, tornem-se crimes violentos. Segundo Chrispino (2007), os conflitos surgem naturalmente do convívio social, e não seria diferente na escola, devendo ser identificados e abordados de forma adequada, para evitar que "explodam" em situaçóes de violência.

Uma série de medidas oriundas de governos locais e estaduais vêm sendo colocadas em prática no Brasil. Algumas delas envolvendo a introdução de práticas militares ou de administração militar nas escolas, como demonstraremos adiante.

\section{Militarizaçáo como forma de Enfrentamento da Violência?}

Na chamada "modernidade tardia", a percepção individual de fragilidade e, assim, a sensação de insegurança têm levado à busca incessante por redução de riscos à segurança (Giddens, 2002). O 
medo da violência vem demandando respostas cada vez mais efetivas, bem representadas pela vigilância constante (Bauman, 1999). Como a escola não é, e não pode ser, uma instituição hermeticamente fechada, reproduz tais características, de forma que casos de violência têm ganhado enorme notoriedade (Da Silva e Assis, 2018).

A preocupação com a violência escolar, no Brasil, não é injustificada. Seu impacto pode ser vislumbrado a partir de pesquisa realizada ao redor do mundo pela Organização para a Cooperação e Desenvolvimento Econômico (OCDE). Neste levantamento, que envolveu mais de 100 mil professores e diretores do segundo ciclo do ensino fundamental e do ensino médio, contando com alunos de 11 a 16 anos, o Brasil apareceu na primeira colocação entre 34 países pesquisados (OCDE, 2014).

A pesquisa da OCDE é a mais importante do tipo e considera dados de 2013. Na enquete, 12,5\% dos professores brasileiros sofrem com agressóes verbais ou intimidação de alunos ao menos uma vez na semana. O índice brasileiro é o mais alto entre os países pesquisados, nos quais a média é de 3,4\%. Curiosamente, os professores da Coreia do Sul, Malásia e Romênia não relataram sofrer esse tipo de violência (OCDE, 2014).

Essa é uma face alarmante do problema de segurança pública que tem ocupado grande espaço nas discussóes políticas, seguindo diversos caminhos de acordo com as instituições decisórias vigentes (Fabretti, 2015). Nesse contexto, aumentam concomitantemente os questionamentos, controvérsias e embates no que tange às ações e instituições de segurança pública, especialmente relacionadas ao policiamento e às polícias (Lemes e Garrido, 2017).

No caso do Brasil, a partir do Governo Militar (1964 a 1985), com o Decreto-Lei de Segurança Nacional, a violência comum aproximou-se da violência política, passando a figurar nas primeiras páginas de jornais (Da Silva, 2014). Ainda de acordo com esse autor, a ordem social passou a se concentrar nas garantias coercitivas de continuidade das rotinas cotidianas imediatas (Da Silva, 2014, p. 29). Talvez essa característica, associada à hierarquia e disciplina militar, bases da organização das Forças Armadas (art. 142 da Constituiçáo Federal, 1988), e à própria presença de tropa uniformizada, que se torna um emblema do poder coercitivo do Estado (De Oliveira, 2016), tenha permitido construir, no Brasil, a ideia de que o militarismo poderia resolver problemas gerais relacionados à violência em qualquer área do convívio social, como na educação.

Curiosamente, mesmo após mais de trinta anos de democratização, essa percepçáo de que o militarismo possa ser uma garantia de redução da violência não diminuiu, mas, pelo contrário, temos visto um recrudescimento destas propostas. Um exemplo disso, é o número crescente de aplicação das Forças Armadas em operações de Garantia da Lei e da Ordem (GLO). Somente na década de 2010, ainda em curso, a Presidência da República decretou quase 30 vezes operaçóes de GLO, com gasto de R\$ 1,4 bilhão. Em comparação, no período de 2011 e 2015, os gastos com a Secretaria Nacional de Segurança Pública, não ultrapassaram R \$ 49,9 milhóes (Caballero, 2017).

É certo que a "garantia dos poderes constitucionais e, por iniciativa de qualquer destes, da lei e da ordem” também são atribuiçôes constitucionais das Forças Armadas (art. 142 da Constituição Federal). Estas devem atuar de forma subsidiária e podem apresentar feição interventiva, de iniciativa do Presidente da República ou em atendimento a pedido manifestado por quaisquer dos poderes constitucionais, por intermédio dos Presidentes do Supremo Tribunal Federal, do Senado Federal ou da Câmara dos Deputados, em acordo com os governantes estaduais, respeitando o pacto federativo. (Garrido, 2018) 
Nesse contexto, além do grande número de decretos de operações de GLO, em 2018, através do Decreto $\mathrm{n}^{\circ}$ 9.288, foi decretada uma intervençáo federal na segurança pública do Estado do Rio de Janeiro. A despeito de se apresentar sob o manto de uma atividade civil, está sob comando militar, pois literalmente "o cargo de Interventor é de natureza militar".

Outro exemplo contundente, que diz respeito ao objeto deste artigo, é o movimento aqui denominado de militarização de escolas públicas. Militarização, segundo o dicionário da língua portuguesa, é o ato ou efeito de militarizar, de dar a algo ou a alguém feição militar. Sendo que, para além do uniforme e da rotineira utilização de armamento, o que melhor ilustra essa feição militar é a prática da Ordem Unida.

No caso da escola de Ítalo, citada logo ao início deste artigo, em epígrafe, aconteceu assim (Camporez, 2018):

Em 19 de julho de 2015, depois de um projeto de lei aprovado pela Assembleia Legislativa do estado, o então governador de Goiás, Marconi Perillo (PSDB), transferiu a gestáo do colégio estadual Waldemar Mundim para a PM. Em uma transição que demorou menos de um mês, a direçáo civil do colégio foi destituída e um coronel da reserva foi indicado para assumi-la. Outros 16 policiais foram escalados para a missão de implantar um novo modelo de ensino, baseado num regimento de 74 páginas escrito pelo Comando de Ensino Policial Militar, subordinado à Secretaria Estadual de Segurança Pública e que tem a Secretaria de Educaçáo apenas como parceira. No mesmo ano em que o Waldemar Mundim foi transferido aos militares, outras 14 escolas de Goiás passaram pelo mesmo processo, e salas e corredores viraram "alas" e "pavilhões".

Segundo o Manual de Campanha C 22-5 do Exército Brasileiro (EB, 2000), a Ordem Unida se caracteriza por uma disposição individual e consciente altamente motivada, para a obtenção de determinados padróes coletivos de uniformidade, sincronização e garbo militar. $\mathrm{O}$ manual propóe que deve ser enxergada por todos os participantes - instrutores e instruendos, comandantes e executantes - como um significativo esforço para demonstrar a própria disciplina militar, isto é, "a situação de ordem e obediência que se estabelece voluntariamente entre militares, em vista da necessidade de eficiência na guerra". Para citar um exemplo, a expressão Pelotão, Alto!, que inicia o título deste artigo é um comando que se destina a fazer com que a tropa pare, interrompendo o movimento de marcha.

Ainda de acordo com o mesmo manual, a Ordem Unida tem por objetivos: proporcionar aos militares e suas unidades os meios de se apresentarem e de deslocarem em perfeita ordem, em todas as circunstâncias estranhas ao combate; desenvolver o sentimento de coesão e os reflexos de obediência, como fatores preponderantes na formação do soldado; constituir uma verdadeira escola de disciplina; treinar oficiais e graduados no comando de tropa; e possibilitar que a tropa se apresente em público, quer nas paradas, quer nos simples deslocamentos de serviços, com aspecto enérgico e marcial. Trata-se, assim, de uma atividade tipicamente militar, com propósitos de formação para a hierarquia, a disciplina e o combate.

Essas características militares, sobretudo a prática da Ordem Unida e sua introdução em atividades rotineiras (por exemplo, nas formaturas matinais diárias e no momento de "avançar" para 
as refeiçôes), para além dos quartéis, são encontradas nos Colégios Militares. Estes são instituiçôes com caraterísticas específicas que têm como proposta ministrar a educação básica, nos anos finais do ensino fundamental (do $6^{\circ}$ ao $9^{\circ}$ ano) e no ensino médio. Nesses estabelecimentos - no total de treze, no Brasil, em 2018 - o ensino é realizado em consonância com a legislação federal de educação e obedece às leis e aos regulamentos em vigor no Exército, em especial às normas e diretrizes do Departamento de Ensino e Cultura do Exército Brasileiro, órgão gestor da linha de ensino do Exército.

Contudo, este texto não trata dos Colégios Militares. Nestes estabelecimentos as características militares são uma opção pedagógica, tal como ilustra, por exemplo, o projeto pedagógico do Colégio Militar de Brasília (CMB, 2015), situado no Distrito Federal. Dentre outros objetivos, ele se "propóe a permitir ao aluno desenvolver atitudes e incorporar valores familiares, sociais e patrióticos que lhe assegurem um futuro de cidadáo patriota, cônscio de seus deveres, direitos e responsabilidades e ainda despertar vocaçóes para a carreira militar”.

Por outro lado - e este é um aspecto extremamente relevante a ser considerado - o ingresso nos Colégios Militares é uma opção dos pais dos alunos, como se verifica, de forma resumida e também exemplificativa, na Proposta Pedagógica do Colégio Militar de Brasília (CMB), ao afirmar que os pais que optam pelo colégio para realizar a educação de seus filhos acreditam nos valores que orientam o Colégio e desejam "que seus filhos absorvam a cultura, a tradição, o modo de fazer e de agir do Exército Brasileiro num ambiente hierarquizado e disciplinado".

Diferente disso, nas situaçóes consideradas neste artigo se está diante de escolas públicas cuja proposta pedagógica não compreende nem se destina à formação ou à atuação militar, mas sim propiciar formação para a diversidade da população brasileira. A Constituição da República Federativa do Brasil estabelece que a educação é um direito social e define algumas atribuiçóes para a efetivação desse direito. Os municípios cuidam da educação infantil e do ensino fundamental. O ensino médio é prioridade dos governos estaduais e do distrito federal, mas estes também gerem o ensino fundamental, em um sistema de gestão compartilhada. Finalmente, a União exerce coordenação financeira e técnica do sistema, além de responsabilizar-se pelas Universidades Federais. Cuida-se aqui, portanto, de escolas e universidades públicas, de responsabilidade do governo civil, portanto instituiçóes civis.

Contudo, nessas escolas públicas vêm sendo introduzidas determinadas rotinas militares, em maior ou menor grau, como resposta desesperada em face do aumento do número de casos de violência escolar, nos mais diferentes estados e cidades brasileiras. É disso que trata o item seguinte.

\section{Militarização da Administração Escolar}

Conforme De Oliveira (2016), a cultura do medo e a violência tem fortalecido a ideia de que é preciso preparar as instituiçóes para agirem de forma dura contra as "ameaças". Nesse contexto, não seria surpresa que as propostas de intervenção militar ou militarizada também aparecessem em outras áreas, como na educação. Isto vem acontecendo em alguns estados e cidades brasileiras já há algum tempo. (p. 46)

Muitas escolas públicas passaram a ser administradas por instituiçôes militares, sobretudo a Polícia Militar (PM), em diferentes estados brasileiros. Vale destacar que, no Brasil, há nos estados e no distrito federal polícias civis, com atuação judiciária e a apuração de infraçóes penais, e polícias militares, que atuam no policiamento ostensivo e na preservação da ordem pública. A PM subor- 
dina-se ao governador, mas segue a mesma hierarquia das Forças Armadas, sendo forças auxiliares e reservas do Exército. (art. 144 da Constituição da República Federativa do Brasil)

Nesse ponto, torna-se necessário distinguir entre gestão e administração escolar. Segundo Martins (2010), administração escolar é o processo racional de organização, comando e controle das atividades escolares, envolvendo o ambiente de trabalho, a atuação dos profissionais envolvidos, a solução de problemas, dentre outros. Já a gestão caracteriza-se pelo reconhecimento da importância da participação consciente e esclarecida das pessoas nas decisões sobre a orientação e o manejo do seu trabalho. Segundo esse autor (Martins, 2010), "a gestão está associada ao fortalecimento da ideia de democratização do processo pedagógico, entendida como participação de todos nas decisões e em sua efetivação". (p. 182)

Assim, parece importante em um projeto de gestão escolar - não limitada a mera administração escolar - que a instituição seja conduzida em relação integrada com a comunidade, e não de forma impositiva. Para tanto é necessário que os seus participantes tenham consciência de que são eles que a produzem com o seu trabalho e agindo em conformidade com essa consciência (Martins, 2010, p. 182). De modo que a imposição de uma cultura militar nas escolas, por se tratar de uma imposição, e não de uma demanda da comunidade escolar, torna-se extremante questionável.

Especificamente no contexto local da pesquisa que deu origem às reflexóes contidas neste artigo (isto é, a partir do município de Petrópolis, estado do Rio de Janeiro, Brasil), não identificamos projetos tendentes a transferir para militares a administração de escolas. Na região sudeste do país, ao que parece, não foram localizados casos dessa natureza - diferente do que ocorreu no estado de Goiás, situado na região centro-oeste, conforme notícia citada ao início deste artigo, de que voltaremos a tratar mais adiante.

Contudo, algumas iniciativas correlatas, embora pontuais, chamaram a atenção no município de Petrópolis, onde vem sendo observado um crescimento de atos de violência escolar, tais como: agressões recíprocas entre alunos; furtos de equipamentos, sobretudo aparelhos celulares; danos ao patrimônio e atos de vandalismo.

A pesquisa em questão tem natureza qualitativa e envolve professores e alunos de graduação e de pós-graduação em Direito da Universidade Católica de Petrópolis, Brasil. Vem sendo realizada desde 2017, sobretudo por meio de observaçóes e entrevistas não estruturadas (informais), buscando compreender a forma como esses casos são administrados e as circunstâncias que os levam a transformar-se até mesmo em açóes cíveis e criminais, com graves repercussóes para os envolvidos.

Tratando-se de uma pesquisa em andamento é necessário esclarecer que, até o momento, foram entrevistadas 3 diretoras de escolas; 3 professores; 4 estudantes do ensino médio; 2 conselheiros tutelares e 1 estagiária de um conselho tutelar. Para evitar qualquer tipo de exposição desses interlocutores, os seus nomes e as instituições em que atuam não serão identificados. Sendo bastante informar que estamos considerando escolas públicas (administradas pelo Estado e pelo Município) e particulares (empresas privadas) situadas na cidade de Petrópolis.

Uma das recorrências identificadas na interação com esses interlocutores revela que os profissionais envolvidos não sabem muito bem como proceder diante dois conflitos escolares e casos de violência. Afirmam, em síntese, que não receberam preparação específica para isso.

Outra percepção proporcionada por essa abordagem empírica diz respeito ao receio/pudor que os profissionais envolvidos têm de prestar informaçóes sobre os conflitos existentes em suas respectivas escolas. Embora também se trate de uma recorrência, tal percepção foi especialmente alimentada 
por uma situação específica. Ao comparecer a uma escola particular da cidade para buscar informaçôes e realizar entrevistas pertinentes à pesquisa, a pesquisadora foi recebida pela Diretora (também proprietária da escola) mas, logo após, foi dispensada, ao argumento de que, naquela escola, não existiam conflitos para serem objeto de estudo. Afirmou a diretora que: “- aqui náo tem esse negócio de conflito escolar não... melhor você ir procurar em uma escola pública, pois lá sim haverá problemas para você estudar".

Essa postura refratária aos pesquisadores, ao mesmo tempo em que representou uma dificuldade adicional ao desenvolvimento da pesquisa de campo, também levou a uma reflexáo interessante no contexto da investigação. É que os conflitos somente podem ser identificados e adequadamente tratados quando são explicitados e conhecidos. Por outro lado, conflitos que permanecem escondidos, abafados, tendem a explodir em situaçóes de violência (conforme Chrispino, 2007). Logo, fingir que conflitos não existem dentro do ambiente escolar, e esperar que os mesmos sejam resolvidos de forma espontânea, pode ter efeitos semelhantes aos de uma bomba-relógio. Por outro lado, essa postura impede que os envolvidos possam ser capacitados para lidarem de forma adequada com essas situaçóes - o uso das ferramentas da mediação de conflitos escolares, por exemplo.

Talvez por esse motivo as respostas institucionais para tais ocorrências variam bastante, sendo muitas vezes pautadas por improvisos que podem provocar desde uma simples omissão (ignorando o fato ocorrido) até medidas graves e, aparentemente, desproporcionais. Nessa segunda vertente, segundo nossas inferências, a escola afasta-se do papel que deve desempenhar na formação dos jovens e, na intenção de edificar um ambiente seguro para a comunidade escolar, acaba tomando medidas que mais servem para intimidar do que para formar cidadãos, às vezes terceirizando para a Polícia e a Guarda Civil (de feiçôes militares) a imposiçáo da disciplina. Nesse caso, a violência é cometida pela escola.

Em um dos casos examinados, a diretora de uma escola pública municipal disse que, certa feita, foi percebido um cheiro estranho vindo do banheiro, acreditando tratar-se de maconha. Depois de identificar o estudante que se encontrava no local, acionou a Polícia Militar. A diretora contou que, posteriormente, arrependeu-se. Especialmente quando os policiais resolveram retirar o aluno da escola e conduzi-lo algemado para a Delegacia, diante de todos. O aluno nunca mais retornou à escola. Segue um trecho da entrevista:

O inspetor sentiu o cheiro de maconha e me avisou. Eu mesma náo senti, mas outros alunos sentiram. Resolvemos chamar a ronda escolar. Já era um aluno problemático... Confesso que depois até me arrependi, pois achei a atitude dos policiais muito dura. Eles quiseram... dar um exemplo... dar um susto, sabe...

Não temos formação para isso. Minha formação é de professora e depois somos nomeadas para o cargo de direção da escola. Temos palestras esporádicas que são dadas pela secretaria municipal de educação e pelo juiz da Vara da Infância e Juventude. Ou os Conselheiros Tutelares também vão na escola dar palestras, esclarecer... mas na maioria dos casos náo me sinto preparada para lidar com essas situaçóes.

Outra diretora relatou que tem um bom contato com o Comando da Polícia Militar na cidade e que, por essa razão, há uma "combinação" informal para que uma dupla de Policiais, fardados e armados, faça uma "ronda" na escola uma vez por semana, durante o horário de intervalo. Segundo 
a diretora isso contribuiu para "empoderar" os professores, mostrando para os alunos que ali é um local em que precisa haver respeito e disciplina. Por outro lado, conversando com alguns alunos de ensino médio dessa escola, estes revelaram que se sentem intimidados, desconfortáveis, quando isso acontece. Note-se como, nesse caso, a autoridade militar foi identificada pelos gestores da escola como uma forma de evitar episódios de violência.

Tal procedimento, contudo, não pareceu ser uma prática disseminada no contexto do município, mas sim uma situação isolada. Possivelmente derivada do fato da escola em questáo estar situada a cerca de duzentos metros do quartel da Polícia Militar. Por outro lado, a prática pareceu dividir opinióes. Isso porque, embora tenha sido percebida por alguns alunos como uma presença intimidatória, para outros não proporcionou nenhum estranhamento, dando a impressão de que a presença da autoridade policial (ou de sua congênere, a guarda escolar) já estaria naturalizada. Uma de nossas interlocutoras, uma estudante do ensino médio, por exemplo, mostrou-se bastante indiferente em relação ao assunto.

Eu nunca passei por essa experiência não ... (risos). Acho que já vi a ronda escolar na minha escola em caso de briga... Eu, pessoalmente, nunca tive nenhum problema com a ronda não...Nunca aconteceu de ronda escolar comigo. Lá na escola já vi aparecer em caso de briga, briga séria, vem os responsáveis, a ronda... fora isso nunca tive nenhuma experiência não.

Medidas semelhantes, de intensidade e abrangência variáveis, vêm sendo noticiadas pelos meios de comunicaçáo. Em outra cidade do estado do Rio de Janeiro, Barra Mansa, uma ordem de serviço expedida pelo Secretário de Educaçáo do Município determinou que todas as unidades escolares da rede pública municipal devem organizar os alunos em fila indiana para entoar, a cada dia da semana, um hino predeterminado, seguido da oração do Pai -Nosso. Na ordem de serviço, a Secretaria de Educação argumenta que o Pai -Nosso é uma oração "universal" e por isso "aceita pela maioria das manifestaçóes religiosas". Os alunos que se recusarem a rezar devem declarar seu desejo por escrito através de seus responsáveis. Além disso, o documento determina que eles sejam colocados em uma fila separada e levados para a sala de aula apenas após a entoaçấo do hino (Amorim, 2017). Fácil perceber, nessa iniciativa, alguma aproximação com a Ordem Unida, atividade própria dos quartéis e colégios militares.

Já no Estado de Goiás, onde o número de escolas públicas que foram transferidas para o comando da Polícia Militar já está próximo de cinquenta (segundo dados divulgados no ano de 2018), o governo tem apontado a militarização como essencial para:

I) a melhoria da qualidade do ensino; II) a melhoria da noçáo disciplinar de alunos e; III) também - em alguns colégios onde o convívio com a sensação de insegurança é mais alarmante - para a maior segurança de alunos em colégios de regiōes mais "inseguras" e, também, para a maior segurança do bairro/regiáo que abriga a escola, uma vez que esta regiáo agora contaria com um "quartel" dentro de si. (De Oliveira e Viegas, 2016, p. 13 e 14)

O movimento de militarização das escolas - ou de transferência da administração das escolas para a Polícia Militar - é apresentado, assim, de forma altamente positiva pelos seus entusiastas. 
Contudo, nem tudo são flores. Diversas críticas recaem sobre essas iniciativas, tanto do ponto de vista pedagógico, quanto em relação aos resultados efetivos no tocante à prevenção e resolução de conflitos. A "solução" encontrada por essas instituições é vista por alguns educadores como uma forma da escola "fugir" do problema.

Para Miriam Abramovay, educadora brasileira responsável por coordenar pesquisa da Unesco sobre o assunto - a atitude mostra um certo desespero da escola, que atesta sua incapacidade para resolver a questão. Segundo essa educadora "militarizar a escola é algo muito grave, porque a escola atesta que ela não é capaz de nada, que para ela funcionar, tem que vir gente de fora, tem que vir a polícia. E aí dizem que isso resolve, mas resolve pela repressão”. (Mendonça, 2014)

\section{Consideraçóes Finais}

Tornou-se alarmante, no Brasil, sobretudo na última década, o crescimento dos casos de violência escolar. Desse fenômeno são vítimas não apenas os alunos, professores, e outros atores que integram a chamada comunidade escolar, mas toda a sociedade brasileira.

Os efeitos dessa grave circunstância ainda não foram dimensionados, mas geraçóes de estudantes estão sendo gravemente comprometidas, demandando medidas urgentes no tocante à prevenção e enfrentamento das situaçóes violentas.

No entanto, ao se discutir tais açóes na escola, não se pode partir da intimidação que só amplifica a violência, olvidando o principal papel das instituiçóes de ensino.

A proposta do artigo foi documentar e colocar sob discussão iniciativas de militarização das escolas ora levadas a efeito, no Brasil, como resposta desesperada para esse quadro de recrudescimento da violência. É preciso refletir mais profundamente sobre essas opçóes institucionais.

A escola é tida como "espaço privilegiado para produção de diálogos, consensos e decisóes, por fim, de facilitação e orientação sobre formas adequadas de resolução e conflitos” (Pinto, 2015, p. 185), sendo esta uma percepção que deve se fazer presente nos processos de tomada de decisão pertinentes ao tema.

Tendo em mente a promessa constitucional de proteção e promoção das liberdades individuais, a introdução de um ensino hierarquizado é algo que necessita ser colocado sob discussáo. Impor às escolas públicas, de forma maciça, a inserção de práticas e hábitos militares é medida altamente questionável do ponto de vista jurídico, e de duvidosa eficácia - segundo abalizadas opinióes, no campo da educação e da pedagogia

É um erro acreditar que tão somente a prática da Ordem Unida pode levar à disciplina e, com isso, a redução dos conflitos. A violência na escola é reflexo da violência disseminada, de forma mais ampla e diversificada, na própria sociedade brasileira. $\mathrm{O}$ problema precisa ser enfrentado, é verdade. Mas sem abrir mão das conquistas democráticas e sem desconsiderar a diversidade - em todos os sentidos, de raça, cor, sexo, tradiçóes, opçóes religiosas, políticas, etc - que é característica marcante da sociedade brasileira, inclusive protegida constitucionalmente.

\section{Agradecimentos}

O segundo autor agradece ao CNPq pelos recursos provenientes da Chamada Universal 2016. Processo: 401928/2016-0. Projeto: Estudo de Casos de Judicialização e Mediação de Conflitos Escolares em Petrópolis, RJ. 
O primeiro autor agradece à FAPERJ pela Bolsa Jovem Cientista do Nosso Estado.

\section{Referências}

Abramovay, M., Castro, M.G., Da Silva, A.P. e Cerqueira, L. (2016). Diagnóstico Participativo das Violências nas Escolas: falam os Jovens. FLACSO - Brasil, OEI, MEC. Recuperado de https:// bit.ly/1oyxANI

Aguinsky, B.G., Silva, G.M.da, Pacheco, C.L. e Ávila, L.deF. (2014). Judicialização dos Conflitos Escolares: desafios para a materialização dos princípios do SINASE. Em M. Isabel Barros Bellini. (Orgs). Anais do II Seminário Regional Políticas Públicas, Intersetorialidade e Família: Formação e intervenção profissional. (13p.) Porto Alegre: PUCRS. Recuperado de https://bit.ly/2J2tglO

Amorim, D. (2017). Prefeitura de Barra Mansa determina que alunos rezem o Pai Nosso na rede pública de ensino. Jornal O Estado de São Paulo, em 12 de outubro de 2017. Recuperado de https://bit.ly/2RXxIX7

Bauman, Z. (2013). Vigilância Liquida. Rio de Janeiro: Jorge Zahar.

Caballero, M. (2017). Diagnóstico Reação em Vez de Prevenção. A Guerra do Brasil. Jornal O Globo. 14 de dezembro de 2017, p.8.

Camporez, P. Número de escolas públicas "militarizadas" no país cresce sob o pretexto de enquadrar os alunos. Revista Época. 23 de julho de 2018. Recupreado de https://glo.bo/2v2q5F2

Charlot, B. (2002). A violência na escola: como os sociólogos franceses abordam essa questão. Sociologias, 4(8), 432-443. http://dx.doi.org/10.1590/S1517-45222002000200016

Chrispino, A (2007). Gestão do Conflito Escolar: da classificação dos conflitos aos modelos de mediação. Revista Ensaio: Avaliação de Políticas Públicas em Educação. 15(54), 11-28. Recuperado de http://www.scielo.br/pdf/ensaio/v15n54/a02v1554.pdf.

CMB - Colégio Militar de Brasília (2015). Missão / Proposta Pedagógica. https://bit.ly/2OBzDmo

Da Silva, L.A.M. (2014). Violência e ordem social. Em R Sérgio De LIMA R.S., R. Ghiringhelli de Azevedo e J Luiz Ratton (Orgs). Crime, Polícia e Justiça no Brasil (pp.26-34). São Paulo:Ed. Contexto.

Da Silva, F.R e Assis, S.G. (2018). Prevention of school violence: a literature review. Educ. Pesqui., v. 44, e157305. http://dx.doi.org/10.1590/s1517-9702201703157305

De Oliveira, D.D. (2016). As escolas militares: o controle, a cultura do medo e da violência. Em I Caetano De Oliveira e V Viegas (Orgs) Estado de Exceção Escolar: uma avaliação crítica das escolas militarizadas (pp.41-49). Aparecida de Goiânia: Escultura produçóes editoriais.

De Oliveira, I.C. e Viegas, V. (Orgs) (2016). Estado de Exceção Escolar: uma avaliaçâo crítica das escolas militarizadas. Aparecida de Goiânia: Escultura produçóes editoriais.

EB - Exército Brasileiro (2000). Manual de Campanha. ORDEM UNIDA. 3aed. Brasília: EGGCF. Recuperado de https://bit.ly/2AhuzdQ

Filpo, K.P. (2016). Conflitos Escolares, Espiral do Conflito e (por que não?) a mediação. Em A Goulart de Sena Orsini,A Silva Maillart e N Dos SANOS (Orgs.). Formas Consensuais de Solução de Conflitos. XXIV Congresso Nacional do CONPEDI - UFMG/FUMEC/Dom Helder Câmara. (pp.357-374). Florianópolis: CONPEDI. http://dx.doi.org/10.26668/IndexLawJournals/2525-9679/2015.v1i1.401 
Garrido, R.G. e Giovanelli, A. (2015). Ciência Forense Uma Introdução à Criminalistica. 2. ed. Rio de Janeiro: Projeto Cultural.

Garrido, R.G., Morell, A. e Azevedo, S.V. (2018). Armed Forces as Security Agency and The Competence of Military Courts: The Prospect of Democratic Breakdown. RBDPP. 4(3), no prelo.

Giddens, A. (2002). Modernidade e identidade. Rio de Janeiro: Jorge Zahar.

Lemes, T. M. De A. e Garrido, R.G. (2017). Transformações das Instituiçóes de Segurança Pública Brasileira e seus Reflexos no Reconhecimento do Mandato e na Accountability. Revista Direito \& Paz. 1(36), 217-233. Recuperado de https://bit.ly/2q5fJS5

Martins, J. P. (2010). Gestão Educacional: uma abordagem critica do processo administrativo em educação. Rio de Janeiro: Wak editora.

Mendonça, R. Goiás aposta em 'militarização' de escolas para vencer violência. BBC Brasil, 26 de agosto de 2014. Recuperado de https://bbc.in/2J2XFAo

Minayo, M. C.de S. (2006). Violência e Saúde. Rio de Janeiro: Fiocruz.

OCDE. TALIS 2013 (2014) Technical Report. Paris: OCDE Publications. Recuperado de https:// bit.ly/2AhmANX

Pinto, N. M. (2015). Percepçóes de jovens sobre conflitos e violências na escola. Dilemas - Revista de Estudos de Conflito e Controle Social, [S.l.], 165-187. Recuperado de https://bit.ly/2PDTL3v

Teixeira, G. (2011). Manual Antibullying para Pais, Alunos e Professores. Rio de Janeiro: Best Seller. 